\title{
4 Development of the mastoid process
}

A The diploic type has large and numerous air cells containing marrow spaces.

B Wittmaack suggested that disease processes, in particular infantile otitides, prevent normal mastoid pneumatization.

C Diamant suggested that hypocellularity of the mastoid is merely a normal variant.

D Both the Tumarkin and the mastoid plate distraction theories of mastoid pneumatization depend on satisfactory middle ear ventilation.

E Only about $50 \%$ of mastoids are pneumatized.

\section{Anatomy of the external ear}

A The auricular skin is loosely adherent to the underlying perichondrium of yellow elastic cartilage.

B The external meatus has the temporomandibular joint as an anterior relation, the mastoid antrum posterosuperiorly and the middle cranial fossa superiorly.

C The great auricular ( $\mathrm{C} 1$ and $\mathrm{C} 2$ ), the vagus and the trigeminal nerves supply sensation.

D The blood supply is from branches of the external carotid artery.

E The lymphatics of the lobule drain to the external jugular lymph nodes.

\section{In the adult}
A The external meatus is $25 \mathrm{~mm}$ long and the bony inner two thirds is directed medially and inferiorly.
B The bony portion of the external meatus is lined by skin bearing glands and hairs.
C The yellow elastic cartilage of the outer one third of the meatus is deficient superiorly.
D Skin lining the bony meatus is closely adherent at the tympanomastoid and squamotympanic sutures.
E The pain of meatal furunculosis is due to a mild osteitis. 